\title{
Development of Portfolio Theory: Pricing Deformations and Autonomous Self-regulation of the Financial Market
}

\author{
Artur R. Nagapetyan*
}

Egor V. Skaletckii

Jakhongir K. Khamdamov

Laboratory management and control systems, Far Eastern Federal University, Russian Federation *Corresponding Email: art9309@mail.ru

\section{Doi:10.5901/mjss.2015.v6n6s7p237}

\section{Abstract}

Scientists are looking for a single model of the financial markets. This model must take into account the whole complex of the identified factors and effects, including the achievements of behavioral economics. The scientific novelty of the proposals in this paper is combination the financial prerequisites of the neoclassical school and the achievements of the behavioral finance researchers in a single model. We propose to introduce the concept of the relative value of one percent of the possible positive earnings and the relative value of one percent of the possible negative income. This allows using the mechanism of implicit arbitrage. We also offer a way for the empirical evaluation of the parameters that we offer to make. The results can serve as a basis for the design and evaluation of financial instruments to identify and overcome the preconditions of pricing deformations in the context of modern portfolio theory and autonomous self-regulation of the financial market.

Keywords: efficient market hypothesis, capital assets, arbitrage pricing model, behavioral finance, new ventures growth, entrepreneurship

\section{Introduction}

It is necessary to provide conditions for the optimal allocation of investment resources in the context of their location in terms of the parameters of 'risk-return'. Scientific substantiation of differences in the efficiency of financial markets in developing and developed economies is important (Fama, 1970). It let evaluate risks more accurate and create conditions for long-term investments for developing countries from international investors. In our study, we consider two basic methodological approaches to modeling of financial markets: the financial methodology of neoclassical school and methodology of the behavioral finance school.

According to our basic hypothesis, the pricing deformations in financial markets arise under the influence of the resulting exposure of economic agents' behavioral abnormalities. The scientific novelty of the proposals in this paper is combination the financial prerequisites of the neoclassical school and the achievements of the behavioral finance researchers in a single model. We propose to introduce the concept of the relative value of one percent of the possible positive earnings and the relative value of one percent of the possible negative income in the standard neoclassical model of financial market.

The authors found a factor impeding integration of behavioral prerequisites in the neoclassical model. Philosophy of Economics offers two opposing ways for proving of the scientific knowledge's verity. The behavioral school of finance use first way. It means that, a statement is right because it has right prerequisites, conditions and assumptions and vice versa (Avtonomov \& Belyanin, 2011).

In the neoclassical approach, the validity of the model depends on its predictive ability, thus the conditions and prerequisites, which define the model, find their admissibility based on coincidence effects, predicted in the model and observe in reality.

The aim of this article is suggestion a modification of the neoclassical model showing the process of expected return calculation for assets and thereby creating a demand for it, including variables that demonstrate the impact of economic actors' behavioral abnormalities. 


\section{Literature Review}

For the first time, Markowitz (1952) carried out a systematic modeling pricing of financial instruments in the context of portfolio analysis for making financial investments. The results were presented in 1952. Proposed portfolio model introduced a new criterion for assessing the effectiveness of investment in terms of the number of units of return per unit of risk. During the further development of these ideas, scientists identified two basic methods of regulating rates of portfolio return-risk, namely, the diversification and the inclusion in the portfolio of risk-free assets. In the micro-level it was about the interests of individual economic agents, in the macro level, it was a question about the formation of a unified model of the functioning of financial markets. However, before these models were offered, Roberts (1967) and Fama (1970) created and developed the conceptual apparatus for new theory - the theory of 'Efficient market hypothesis'.

According to this hypothesis, the information efficiency of the financial market as the ability to autonomously take into account the newly arriving information in pricing of assets is a necessary and sufficient condition for the optimal allocation of scarce financial resources in the economy (according to the criterion of return-risk). Sharpe developed 'Capital assets pricing model' (CAPM) in 1964 (Sharpe, 1964). Ross developed 'Arbitrage Pricing Model'(APM) in 1976 (Ross, 1976). Both models interpret the equilibrium state of the market in terms of its information efficiency. Furthermore, with the development of mathematical tools, scientists developed models describing various mechanisms for evaluation of financial assets pricing. For example, Black and Scholes proposed option-pricing model in 1973 (Black \& Scholes, 1973). However, since the 1970s, some scientists developed alternative views that interpret the processes taking place in the financial markets. This was largely because the fundamental premise of rationality of economic agents, which is a prerequisite for confirmation of 'Efficient markets hypothesis' (EMH) is not always borne out in practice. Although this hypothesis (EMH) may occur even in case if only some of investors are rational agents, but there was the concept of bounded rationality which was created by Simon (1978), and further developed by Shiller (1981). Kahneman and Tversky (1979) offered 'Prospect theory' in 1979, which almost questioned the possibility of allocating rational agents in simulation of economic processes. Many authors attempted to offer a theory that would reconcile the fundamental contradiction in the above models. In our view, a serious potential has an 'Adaptive market hypothesis' that was proposed by Lo in 2004 and based on an evolutionary approach to economic interactions (Lo, 2004). In addition, there are interesting findings in Estrada, associated with features of the emerging markets (Etrada \& Serra, 2005; Estrada, 2009).

The creator of the APM argued that a large part of modern financial theory is based on the explicit or implicit using in economic evidence of the judgments' truth of about the theoretical concept of achieving states in which there are no arbitrage opportunities (Ross, 1978). Today, in theory arbitration mechanisms are crucial in the consideration of all financial processes.

Today, there are one more very useful concept - diversity. Scientists use it in different theories and spheres, but we are sure this concept as well as arbitrage will be very important in any disciplines, especially in philosophy, sociology, and economics (Ross, 1973). Philosophical works (including our study) in the field of potentials of existence and the internal contradictions of 'diversity' on the one hand, and researches of scientists in the field of system analysis and system concepts have the critical importance in this case (Avtonomov \& Belyanin, 2011).

We convinced that attempts of socialization and integration of the concept of 'diversity' in the philosophy of sociology and economics (including in financial economics), search for the determinants of its nature, potential endogenous problems, mechanisms for their identification and overcoming will be the priorities of research in the future (Smirnov \& Belkin, 2015).

Arbitrage is the main instrument that defines the key concept of pricing deformations. It allows us to interpret and to identify it. In addition, we get a possibility to overcome the impact of economic agents' behavioral abnormalities. The concept of arbitrage (in the financial science) means investment strategy that provides a guaranteed positive return (exclude the possibility of loss), while net investment is equal to zero (Ross, 1976). Arbitrage (in accordance with the generally accepted in the humanities approach) allows us to form a rigorous theoretical schemes, where there may the equilibrium state of the system without opportunities for arbitrage operations. We suggest considering the state when there are even the potential possibility of arbitrage operations, as the situation with the presence pricing deformations.

In this case, next research question is formed. How can we identify and overcome the pricing deformations?

\section{Research Methods}

We presented the hypothesis that the deformation of pricing in financial markets arise under the influence of the resulting effects of economic agents' behavioral abnormalities. In this case, we can expect that the price dynamics contain 
information about the assumptions of deformations at each subsequent time. It is important to distinguish this statement from the approval of the possibility to predict future prices based on their past, which contradicts even the weak form of the EMH. There are many behavioral abnormalities, which interfere agents to make decisions. Kahneman studied these factors in more detail (Kahneman \& Tversky, 1979). In order to demonstrate the essence of our new variables, we need to represent the neoclassical model for estimating the expected return (which can measure the demand for an asset). In the theory of rational expectations, demand for assets depends on the expected income, that is potentially possible, multiplied by a measure of the risk (probability of), depending on investor confidence in the fact of income (1).

$$
\begin{aligned}
& D \sim \frac{P_{1}}{P_{0}} * R \\
& \text { where, } \mathrm{D} \text { - the level of demand for the asset } \\
& \mathrm{P}_{1} \text { - the expected price of the asset in the future } \\
& \mathrm{P}_{0} \text { - the current price of an asset } \\
& \mathrm{R}-\text { the level of risk (the probability of a shortfall) }
\end{aligned}
$$

We consider following indices of the global economy: World consumer goods, Americas Consumer Goods, Asia/P Consumer Goods, Europe Consumer Goods and MICEX CGS (Russian equivalent). The company 'Finam' is the largest brokerage company in Russia, it has provided these data. In our work, we did not use Test of higher moment capital asset pricing model (Javid, 2009; Doan et al., 2010). We decided to modify the proposed Estrada model (Estrada, 2007). To do this we used the conclusions conditional asset-pricing model (Iqbal et al., 2010). In our model, we have added two new factors in the standard model. They express the impact of behavioral factors. They show different attitudes of economic agents to the expected income in the future. We believe that investors have different opinions on the same cash flow. They estimate the value of its units in terms of income and the value of its units in terms of losses. Further, when constructing the model, we show how investors can interpret certain deviation estimates. The most controversial part of our work is our proposal for the empirical evaluation of the parameters that we offer to make. To this end, we propose to calculate the coefficient of «B», in the form of « $\left\langle\mathrm{B}^{+} »\right.$ and $\left\langle\mathrm{B}^{-} »\right.$. This is the most important practical proposals in our work. It allows us to model the risk of a new way. It concludes the achievements both the neoclassical school finance and behavioral finance. We find the reaction of objects on rising or the falling of the general index. Since we are talking about the evaluation of the same cash flow, any deviation of these estimates is a signal of pricing deformations. Further, the work we formulate a model that allows us to interpret, identify and overcome the corresponding deformations.

\section{Model and Analysis Results}

Foreign researchers conducted a large number of studies, that test the information effectiveness of financial markets in different countries (Fama, 1970). At first glance, the results of scientific research do not show conclusive evidence, which can deny the EMH. According to the generally accepted definition, the market is efficient with respect to some information set if the disclosure of this information to all participants of the market are not change prices for financial instruments. In recent studies, scientists are considering three levels of market efficiency, which correspond to three different types of information sets. According to the weak form of the EMH, the prices of financial instruments fully reflect all the information contained in the historical data about their dynamics. Most studies confirm compliance this hypothesis with current market parameters. Mild form of the EMH suggests that the current rate of the prices of financial instruments reflect not only all the historical information about their dynamics, but also all publicly available information relevant to the underlying assets of the relevant financial instruments. The strong form of the EMH considers, that market prices fully reflect all information relevant to the subject market assets known to at least one party. Each of the hypotheses under the EMH is based on the concept of so-called post deformation arbitrage. However, if there is a deformation of pricing, the arbitrageurs - economic entities conducting arbitrage operations - realizing their interests, create market pressure on pricing deformations.

In this case, we have an approach based on the method for assessing the financial instruments (Sharpe, 1964). Using this method involves the introduction of certain restrictions and conditions, which generally determines the functioning of rational actors in a perfect market conditions. This approach also are used for formation of such models as the "EMH", the "CAPM", the "APM" and others. In the formula 1, it is assumed that the value of one percent of possible income (both positive and negative) in terms of its income is equivalent to the value of one percent of possible income (both positive and negative) in terms of its losses. It means, that the relative value of one percent of a possible positive return in the future $\left(\mathrm{R}^{+}\right)$is always equal to the relative value of one percent of the possible negative income in the future R-) (Nagapetyan et al., 2015). Intuitively, one can agree with this proposition, because we are talking about the same percentage of possible changes. However, in real life is a prerequisite is often violated. Because of this, we see an opportunity to create a unified model of financial markets based on neoclassical methodology, but takes into account the 
factors influencing behavioral effects (Rubinstein \& Nagapetyan, 2015). Ultimately, we do not need to consider every behavioral abnormalities in particular, we have introduced in the beginning of the hypothesis that we can assess their net effect introduced by the attitude of showing new parameters $\mathrm{R}^{+}$and $\mathrm{R}^{-}$. We represent the neoclassical model for estimating the expected return (it can measure the demand for an asset), with introduced parameters in formula 2.

$$
D \sim \frac{P_{1}}{P_{0}} * R *\left(\frac{R^{+}}{R^{-}}\right)
$$

where, $\mathrm{R}^{+}$- the relative value of one percent of a possible positive return in the future

$\mathrm{R}^{-}$- the relative value of one percent of the possible negative income in the future

In this case, the expression (1) is a special case of the expression (2), with the proviso that $R^{-}$equals $R^{+}$. In order to demonstrate this result in practice we consider consumer goods Indexes in World level, and try to find change reaction of markets in USA, Europe, Asia/P and Russia in positive and negative direction. We use Sharpe approach, supplemented by our model, the results in table 1.

Table 1. The results of the calculation of $B, B+$ and $B$ using our model

\begin{tabular}{ccccc}
\hline coefficient & USA & Europe & Asia & Russia \\
\hline B & 0.887 & 1.282 & 0.762 & 0.668 \\
B $^{+}$ & 0.928 & 1.364 & 0.67 & 0.57 \\
B- & 0.865 & 1.186 & 0.757 & 0.831 \\
\hline
\end{tabular}

Source: based on Finam database, 2015

In cases where, $\mathrm{R}^{+}$is not equal to $\mathrm{R}^{\text {; }}$, we identify predictors of pricing deformations that is determined by the ability of post deformation arbitrage. At this stage we propose to draw attention to the fact that if $\mathrm{R}^{+}$is more than $\mathrm{R}^{-}$, it is possible to talk about preconditions for a possible underestimation of the asset, whereas if $\mathrm{R}^{+}$is less than $\mathrm{R}^{-}$, we can talk about preconditions for a possible revaluation of the asset (20). In the Table 1, we try to evaluate the deviation between $\mathrm{R}^{+}$and $\mathrm{R}$. We felt the modified coefficient $\left\langle\mathrm{B} »\right.$, in the form of $\left\langle\mathrm{B}^{+}\right\rangle$, and $\left\langle\mathrm{B}{ }^{\mathrm{B}}\right\rangle$. Indicator $\left\langle\mathrm{B}^{+}\right\rangle$indicates reaction of the index of the region or country in the growth of the global index by $1 \%$. Indicator «B» shows reaction of the index of the region or country in the growth of the global index by $1 \%$. We see that the results are different from the standard calculation of bilateral «B».

\section{Discussion and Conclusion}

We believe that it is necessary to split the concept of risk into two parts and to introduce new parameters in the standard neoclassical model of expected return evaluation. Parameters of the relative value of one percent possible positive return in the future exactly is equal to the relative value of one percent possible negative income in the future that is, $\mathrm{R}^{+}$is equal to R- only in two situation. It is equal, when the level of risk (the probability of a shortfall) is zero or one. In the first case, the valuation for the investor are the same because the size of the expected cash flow is equal to zero. In the second case, the assessment for the investor are the same because the size of the expected cash flow is fixed. In other cases, where the level of risk is more than zero and is less than one, we establish the inequality $\mathrm{R}^{+}$and $\mathrm{R}$.

How can we identify these deviations? We believe that investors are constantly evaluated the same items on the market. If investors have the same assessment of the object in terms of their possible income or loss, they will respond symmetrically to the poor or good news on the macro level (the change of the global index). This means that $\left\langle B^{+}\right\rangle=\left\langle B^{*}\right\rangle$ $=$ $« B »$. If equality is not satisfied, therefore, investors have different opinions on the same objects when they think about their loss or of their acquisition. The greater the difference between the « $\mathrm{B}^{+} »$ and $« \mathrm{~B} »$, the greater the difference between $\mathrm{R}^{+}$and $\mathrm{R}^{-}$.

In addition, there is another question. How can we interpret these deviations? We believe that there are two approaches. They are associated with the conclusion of the next statement. Is asset Overvalued or undervalued at a given time? On the one hand, if the asset is growing faster in case market growing in comparison with its reaction on the market downturn, we can say that the asset is undervalued. In this case, the investor need to buy it. On the other hand, we can conclude that if the asset is growing disproportionately fast, investors simply overrated it and it is a signal for selling.

The validity of our theses can be presented as a possibility for arbitrage operations. However, it will not be post deformation arbitrage. We offer to consider before deformation arbitrage operations, which will create market pressure on 
the processes of asset pricing, aimed not only to overcome the existing deformations, but to prevent their occurrence, by overcoming their arise presuppositions. It is important to note that we are not talking about prices predestination. We only state the opportunity to avoid pricing deformations. We have given two options for interpretations of practical calculations of our theoretical results. While the authors of this article inclines to the first form of interpretations. In terms of policy recommendations, it suggests that investor needs to sell assets if $\mathrm{R}^{+}$is more than $\mathrm{R}^{-}$and buy assets when $\mathrm{R}^{+}$is less than $\mathrm{R}$; which is quite natural. Thus further studies suggest seek opportunities to identify and implement implicit before deformations arbitrage. This article is intended to constitute a theoretical study and formulation of the hypothesis. In the following paper, we present the results of testing our proposed model, based on our chosen way of evaluating new risk parameters.

\section{References}

Avtonomov, V., \& Belyanin, A. (2011). Behavioral institutions of a market economy: problem formulation. Public Sciences and modernity, 2, 112-130.

Black, F., \& Scholes, M. (1973). The pricing of options and corporate liabilities. Journal of political Economy, 81 (3), 637-654

Doan, P., Lin, C., \& Zurbruegg, R. (2010). Pricing assets with higher moments: evidence from the Australian and US stock markets. Journal of International Financial Markets. Institutions and Money, 20 (1), 51-67.

Estrada, J. (2007). Mean-semivariance behavior: downside risk and capital asset pricing. International Review of Economics and Finance, 16, 169-185.

Estrada, J. (2009). The gain-loss spread: a new and intuitive measure of risk. Journal of Applied Corporate Finance, 21 (4), 104-114.

Estrada, J., \& Serra, A. (2005). Risk and return in emerging markets: family matters. Journal of Multinational Financial Management, 15 (3), 257-272.

Fama, E. (1970). Efficient capital markets: a review of theory and empirical work. Journal of Finance, 25, 383-417.

Finam database (2015). Indexes of international economy. [Online] Available: http://www.finam.ru/analysis/quotes/?0=\&t=5563165 (September 26, 2015)

Iqbal, J., Brooks, R., \& Galagedera, D.U.A. (2010). Testing conditional asset pricing models: an emerging market perspective. Journal of International Money and Finance, 29(5), 897-918.

Javid, A. (2009). Test of higher moment capital asset pricing model in case of Pakistani equity market. European Journal of Economics, Finance and Administrative Sciences, 15, 144-162.

Kahneman, D., \& Tversky, A. (1979). Prospect Theory: An Analysis of Decision under Risk. Econometrica, 47(2), 263-291.

Lo, A. (2004). The adaptive markets hypothesis. Journal of Portfolio Management, 30, 15-29.

Markowitz, H. (1952). Portfolio Selection. Journal of Finance, 7(1), 77-91.

Nagapetyan, A., Rubinstein, E., \& Urumova, F. (2015). The development of modern portfolio theory: pricing deformation and arbitration. Bulletin of the Institute of Economics of Russian Academy of Sciences, 3, 106-115.

Roberts, H. (1967). Statistical versus clinical prediction of the stock market. Chicago: University of Chicago.

Ross, S. (1973). The economic theory of agency: the principal's problem. American Economic Review, 63(2), 134-139.

Ross, S. (1978). A simple approach to the valuation of risky streams. Journal of Business, 51(3), 453-475.

Ross, S.A. (1976). The arbitrage theory of capital asset pricing. Journal of Economic theory, 13(3), 341-360.

Rubinstein, E., \& Nagapetyan, A. (2015). Development of the modern portfolio theory: an implicit arbitrage in the context of identifying the prerequisites of pricing deformations. Theory and practice of social development, 12, 134-136.

Sharpe, W. (1964). Capital asset prices: a theory of market equilibrium under conditions of risk. Journal of Financem , 19, 425-442.

Shiller, R. (1981). Do stock prices move too much to be justified by subsequent changes in dividends? American economic review, 71(3), 421-436.

Simon, H.A. (1978). Rationality as Process and as Product of Thought. Richard Tely Lecture. American Economic Review, 68, 1-16.

Smirnov, V., \& Belkin B. (2015). Experience in the Application of the Principle of Methodological Pluralism in the Study of Entrepreneurship. Asian Social Science, 11(7), 122-127. 